\title{
Eye Tracking in Neuromarketing: A Research Agenda for Marketing Studies
}

\author{
Renê de Oliveira Joaquim dos Santos ${ }^{1}$, Jorge Henrique Caldeira de Oliveira ${ }^{1}$, Jéssica Bonaretto Rocha ${ }^{1}$ \& \\ Janaina de Moura Engracia Giraldi ${ }^{1}$ \\ ${ }^{1}$ Department of Business Administration, University of São Paulo, RibeirãoPreto, Brazil \\ Correspondence: Janaina de Moura Engracia Giraldi, Marketing and Management, Department of Business \\ Administration, University of São Paulo, Av. Bandeirantes 3900, Monte Alegre, Ribeirão Preto (SP), 14040-905, \\ Brazil. Tel: 55-16-3602-3903. E-mail: jgiraldi@usp.br
}

Received: September 2, 2014

Accepted: December 4, 2014 Online Published: February 17, 2015

doi:10.5539/ijps.v7n1p32

URL: http://dx.doi.org/10.5539/ijps.v7n1p32

\begin{abstract}
This article investigates the potential use of Eye Tracking as a neuromarketing tool and its potential for marketing in general. We sought to identify some of the main applications within the mainstream of marketing. The objective of this research was achieved by means of a conceptual literature review. The results of our research indicate important potential uses for Eye Tracking in practical marketing applications, such as brand equity, segmentation, new product development, pricing decisions, place decisions, promotion decisions, and social marketing studies. It is believed that in the near future, neuromarketing tools such as Eye Tracking will be part of mainstream marketing studies.
\end{abstract}

Keywords: neuromarketing, eye tracking, visual attention

\section{Introduction}

This research sought to identify some possible applications of a Neuromarketing tool (NM) called Eye Tracking (ET) in traditional areas of marketing. ET is a tool for the analysis of visual attention and from the perspective of $\mathrm{NM}$, it seeks to associate visual attention with the cognitive and emotional responses of consumers. This issue has attracted increasing interest in recent years (Solnais, Andreu-Perez, Sánchez-Fernández, \& Andréu-Abela, 2013). Consumer neuroscience emerged in the late twentieth century (Martinez, 2011). It deals with the conditions, the psychological significance, and the behavioural consequences that underlie consumption (Reimann, Schilke, Neuhaus, Weber, \& Zaichkowsky, 2011). Consumer neuroscience incorporates both new and more traditional tools that were not commonly used for this purpose.

This paper performed a mapping of ET as a NM tool and identified possible new potential applications of this $\mathrm{NM}$ tool in the area of marketing. ET measures what the user is looking for (the gaze point on the screen), the eye movement in relation to the head, and pupil dilation (Zurawicki, 2010). The different ET systems are able to estimate an eye's point of attachment on a computer screen, or on the shelf of a supermarket, and may determine precisely where the user's attention is directed (Duchowski, 2003). To Hoffman and Subramaniam (1995), eye movements can be seen as an objective indicator of where a person's overt attention is focused and help to filter visual information.

For the present article, secondary sources were consulted based on available publications in major databases such as Scopus, Emerald, ProQuest, Elsevier, Springer, and Science Direct. Thus, this article has a qualitative and exploratory approach, but it is not just a literature review; it also searches to identify potential ET applications for marketing. After analysing recent publications related to neuromarketing and eye-tracking, we have selected the main issues and described some of the potential uses of ET for marketing.

In order to attain these objectives, it should be stressed that the marketing strategy begins with the market analysis that an organisation is considering, a detailed analysis of the organisation's capabilities, the strengths and weaknesses of competitors, the economic and technological forces that affect the market and the potential customers in the market. Based on consumer analysis, the organisation identifies groups, households, or companies that have similar needs. Then, one or more of these segments are selected as target markets based on the potential of the company in relation to competitors. Thus, the marketing mix is prepared: this involves 
determining the product characteristics, price, communication, distribution, and services that will provide more value to the customer. This set of features, which is called total product, is presented to the target market that is constantly involved in processing information and making consumption decisions (Hawkins, Mothersbaugh, \& Best, 2009).

Based on these features reported by Hawkins et al. (2009), topics were listed that were considered classics of marketing and very important for the development of marketing strategies: brand equity, segmentation, product decisions, pricing decisions, place and promotion decisions, and social marketing. This paper analyses the works found in literature that met thesecited topics. Each of these topics served as a grouping criterion for articles involving the use of ET. Before presenting this analysis, some theoretical background on neuromarketing is provided.

\section{Neuromarketing}

In recent years, researchers have increasingly used a multidisciplinary approach in their scientific development, which has led to new insights and discoveries (Javor, Koller, \& Lee, 2013). The use of neuroscientific methods has gained prominence in various marketing applications and has contributed to greater understanding of human behaviour. According to Martinez (2011), NM is the result of the integration of three different disciplines:

- Neurology: focuses on the study of the human brain;

- Cognitive psychology: studies the relationship between mind and human behaviour;

- Marketing: the discipline responsible for developing new, profitable products and services to meet the needs of consumers.

NM focuses on researching and understanding consumer behaviour through studies of the Central and Peripheral Nervous System. NM researchers measure people's responses to marketing stimuli. The development of this field depends on the progress of several fields of study: neuroscience, applied physics, and computer science (Bercea, 2013).

According to Calvert and Brammer (2012), NM is the application of cognitive neuroscientific tools in marketing in order to measure the unconscious responses of consumers. NM is being integrated more and more into traditional market research, incorporating information derived from traditional, explicit tools with new ideas to reveal how consumers really feel.

Therefore, NM is being used to study consumer behaviour and purchase decision processes (Glimcher, Camerer, Fehr, \& Poldrack, 2009) to better understand the effect that psychological phenomena and emotions have on purchasing decisions and to provide a more comprehensive service in assessing the effectiveness of marketing phenomena, such as advertising, the competition over consumer attention, and the insertion of products (Reimannet et al., 2011). NM is a tool that is potentially useful for the development of more effective strategies and action plans for brands, and corresponding business plans (Martinez, 2011).

Neuroscience, when applied to marketing, allows marketing researchers to have a better understanding of the degree of abstraction present in the minds of customers and the role of emotions in decision-making and enables the development of more effective methods for triggering these emotions (Vashishta \& Balaji, 2012). Traditional methods, such as interviews, surveys, or focus groups consider that people are able to describe their own cognitive processes. However, according to some authors, the purchase process happens subconsciously (Butler, 2008; Fugate, 2008; Hubert \& Kenning, 2008; Morin, 2011; Page, 2012). In addition, numerous factors motivate participants to filter the reporting of their feelings about incentives, time cost, or peer pressure (Morin, 2011). It is in this context that vision (and visual attention) plays a role of great importance, since it is one of the main recipients of marketing stimuli.

There are several brain regions related to vision (approximately $25 \%$ of the brain). The processing of visual attention begins when eyes receive light signals. This information leaves the eyes and travels to the brain through specialised neurons called photoreceptors that convert light signals into encoded electrochemical signals (Zurawicki, 2010). According to Russo (1978), eye movements can be considered good behavioural candidates for measuring visual attention and information acquisition because they are closely related to higher-order cognitive processes. Therefore, understanding and monitoring pupil dilation and other patterns in eye movement is an important part of neuroscience for NM.

For Van Praet (2012), cognitive neuroscience today shows that humans make many irrational decisions, that perception can be illusory, and that people's minds in many ordinary occasions are designed for self-deception. Neuroscience data can indicate implicit processes, improve forecasts and the generalisation of behaviour models, 
and provide a reliable approach to segment customers to communicate better with them (Venkatraman, Clithero, Fitzsimons, \& Huettel, 2012).

\section{Eye-Tracking as a Research Tool}

ET measures where the person is looking (gaze or fixation point), the time that this person looked at this certain point, the movement of his eyes in relation to his head, pupil dilation, and the number of blinks (Zurawicki, 2010). In addition to the fixation, the sequence in which his or her eyes shift from one location to another (saccade) can also be evaluated (Chae \& Lee, 2013). There are different ET technologies to measure eye movement and the most common are those that measure the observation of controlled stimuli at fixed points in videos, photos, and user's interaction with a computer screen. There are more advanced devices that also automatically track the head position in three-dimensional space in relation to the camera (Zurawicki, 2010). This makes the measurement process more subtle, with very little or no interaction between the researchers and their subjects.

Studies with ET equipment, although not new, have offered new perspective within neuromarketing. These studies, and the potential of ET, have gained relevance in today's world of the visual pollution that is vying for consumers' attention. Understanding the mechanisms that guide consumers to select certain points of interest in an image (attention standards and forecasting the places of greatest interest) have many applications for the business world (Zhao \& Koch, 2013). Therefore, ET can provide information on what is more relevant to the involvement of attention, as it is related to patterns of visual fixations, in many different marketing issues (Fiszman, Velasco, Salgado-Montejo, \& Spence, 2013).

In addition, ET can also be used with other equipment to measure cognitive responses, lead synergy for new insights, particularly in relation to consumer behaviour and marketing communications. When connected to facial coding, the results show the precise amount of visual activity (exactly where people are looking) associating specific emotional responses to different elements of a stimulus (how people felt about what they saw).

The synchronisation between emotional response and visual focus provides a reliable method for understanding what is driving the reactions to a given stimulus (Hill, 2011). This is of inestimable value, especially for TV advertisements, in which lots of information is generated every millisecond, possibly hindering the identification of what the viewer really liked, or what actually called his attention in a positive or negative way.

The typical model of eye movements applied to the use of eye-tracking consists of two concepts: fixations and saccades (Velásquez, 2013). Nielsen and Pernice (2009) define fixation as the moment when the eyes are fixed on an object and it is possible to enjoy it in detail, while saccades correspond to rapid eye movements between two fixations. As seen in Exhibit 1, in addition to these major movements, ET measures other variables that may be of great value for marketing, such as pupil dilation, pupil size (identification of attention and emotions), and eyelid closure (sleepiness monitoring) among other measures.

Eye fixation usually ranges from approximately 200 Ms during the reading of a text to 350 Ms during viewing of a scene. The saccades movement to the new target takes approximately $200 \mathrm{Ms}$. The resulting series of fixations and saccades is called scan path. Scan paths are used to analyse visual perception, cognitive intent, interest, and relevance. One possible application for marketing is how humans interact with computers, especially the evaluation of web pages and online advertisements (by highlighting the focal points of attention), and behavioural patterns of navigation (Zurawicki, 2010). Other eye-tracking uses have been reported by Chae and Lee (2013), such as the recording and analysis of individuals' visual attention by tracking eyesight in various fields: usability, marketing, cognitive psychology, and behavioural psychology. This method helps in identifying more effective ways of producing online sales and identifying difficulties during the customer checkout process, either with the format or any of the purchasing steps.

Orquín and Loose (2013) argue that the eyes' movement during the decision-making process is partially driven by the requirements of a given task and partly by the properties of stimuli (that are causing a bias in order to capture information) where striking visual stimuli are favoured. The factors that contribute to attention, and influence the meaning of a stimulus to an individual, are top-down and bottom-up factors (Behe, Zhao, Sage, Huddleston, \& Minahan, 2013). To Pieters and Wedel (2004) bottom-up factors are the characteristics of the stimulus itself, and they are a rapid form of attentional capture. Top-down factors, in turn, are previous ideas about the product that consumer already had. Top-down factors require consumers to voluntarily search and pay attention to specific information. 
Table 1 . Variables usually measured by eye-tracking

\begin{tabular}{|c|c|}
\hline $\begin{array}{l}\text { What can be } \\
\text { tracked? }\end{array}$ & Application \\
\hline $\begin{array}{l}\text { Gaze direction } \\
\text { and gaze point }\end{array}$ & $\begin{array}{l}\text { Gaze interaction with computers and other interfaces in behavioural research. } \\
\text { Tests the human response to better understand what attracts people's attention. }\end{array}$ \\
\hline $\begin{array}{l}\text { Detection of eye } \\
\text { presence }\end{array}$ & $\begin{array}{l}\text { Finding the eyes is the first thing the eye-tracking system does and is therefore a } \\
\text { key part of eye-tracking. }\end{array}$ \\
\hline Eye position & $\begin{array}{l}\text { The ability to calculate the eye position in real time is part of what makes the ET } \\
\text { system accurate and precise with regard to visual attention, including studies of } \\
\text { advertising campaigns on television, internet, and cinemas, with no delays in the } \\
\text { processing of this information. }\end{array}$ \\
\hline $\begin{array}{l}\text { Eye } \\
\text { identification }\end{array}$ & $\begin{array}{l}\text { Eye tracking identifies individual ocular characteristics based on geometric } \\
\text { calibration. The geometrical characteristics of the eye and iris identification can } \\
\text { also be used for user identification. }\end{array}$ \\
\hline Eyelid closure & Eyelid closure is used to monitor the attention or sleepiness of people. \\
\hline $\begin{array}{l}\text { Pupil dilation } \\
\text { and size }\end{array}$ & These are reliable measures of emotions and are used in market research. \\
\hline
\end{tabular}

Source: Tobii Technology (2013)

\section{Results of the Literature Review}

This section analyses papers found in literature that explored the following topics: brand equity, segmentation, product decisions, pricing decisions, place and promotion decisions, and social marketing. These studies were not necessarily categorised by the authors as NM studies; however, they may fall within this line of research, also serving as a basis for further related studies.

\subsection{Brand Equity}

A brand is a world of attractions and desires for consumers, so it should be dynamic, active, and present in the life and mind of a consumer, stimulating their brain and generating emotions (Martinez, 2011). Companies build their brand equity (BE) by creating brand knowledge structures with the target audience. Three major BE drivers can be categorised as: initial choices of brand elements (brand name, logos, symbols, characters, representatives, slogans, jingles, packaging, and signs); the product, the service, and all associated marketing activities and support marketing programs; and, finally, other associations indirectly transferred to the brand (Kotler \& Keller, 2009). ET may contribute to the definition of the brand elements by testing with potential consumers and identifying drivers that cause more visual impact.

Research examined the shopping experiences of individuals in an experimental laboratory to determine whether consumers prefer a product with third-party brands or the private label brands owned by supermarkets. Using ET to analyse the process of decision-making, researchers concluded that the purchase decision and the time spent observing the packaging indicates that participants preferred the packaging with widely recognised third-party brands compared to supermarket private label brands (Hurley, Ouzts, Fischer, \& Gomes, 2013). Quantifying this interest through the visual attention given to one brand over a competing brand is another potential use of ET, since it would become a quantifiable parameter to analyse the impact of changes in the variables of BE boosters over time.

Chae and Lee (2013) investigated the impact of using celebrities as human brands on the quality of consumer decisions in an environment of online purchases through the analysis of visual attention using ET. They concluded that using human brands could improve a consumer's decision-making process and improve the quality of their decisions by encouraging intuitive choices and reducing cognitive, emotional effort. They found that the fixation duration on the human brand image (regarded as visual attention in this research) is relatively longer during this high-quality decision. The fixation duration on the human brand image can also increase trust in products and encourage consumers to think positively about the quality of decisions they make (both long eye fixation and high product trust result from high decision quality). Another study on human brands showed that the level of consumer appeal for images of known individuals in online shopping has a significant influence on visual attention and purchase intent for consumers in relation to a product (Chae \& Lee, 2013). 
The convergence of other attention behaviours, such as selecting channels with a TV remote control during advertisements, and attention to the brand, also represent a great potential for ET. Teixeira, Wedel and Pieters (2012) studied the impact of branding activities through the audio-visual representation of brands. They also analysed the focus, attention dispersion, and evasion of consumers during TV advertisements. Using eye-tracking data in association with records of the TV remote control, they analysed 2,000 participants and 31 TV advertisements. Among their findings, the experiment revealed that keeping full and constant brand exposure significantly decrease devasion.

Another study with TV advertisements using ET evaluated the effectiveness of brand presentation when subjects were allowed to fast-forward through advertisements with a remote control until their program resumed. The study concluded that the viewer's attention is strongly limited to the centre of the screen when fast-forwarding. ET can help us to understand the new challenges created with technological changes and their effects on consumers' attention (Brasel \& Gips, 2008). Anticipating this behaviour, advertisements transmitted during fast-forwarding can still bring static images, which would allow advertisers to communicate part of the desired information, like the brand logo, for instance. Clearly, ET has very interesting potential in the study of brands and technologies, revealing many alternatives for bringing the brand to the consumer, even with increasing challenges to maintaining visual attention.

\subsection{Segmentation}

To some extent, every individual has similar needs in relation to most products. However, various segments of the larger market have different needs, and companies seek to target some of these other markets with their advertisements (Hawkins et al., 2009). Segmentation standards based on visual attention behaviours are unusual, but they represent a great potential for marketing since people of different ages, cultures, and educational levels may have different behaviours. On the other hand, any other segmentation criteria would benefit from the knowledge of visual attention behaviour patterns within selected segments of the larger market.

In addition, identifying and grouping different sets of needs that a product or a company can meet involves traditional marketing research, such as focus groups, and in-depth interviews. What these types of research cannot capture, however, are implicit and unconscious information in the decision-making process. The identification of these cognitive processes that lead to individual variability in consumer behaviour can create new approaches for marketing researchers in the task of segmenting potential target markets (Venkatramanet al., 2012). The importance of vision for neuroscience can be evaluated by the proportion of designated space in the brain for the processing of visual images and associations: $25 \%$ of its volume is dedicated to this purpose (Zurawicki, 2010).

ET studies may contribute to measuring these cognitive and behavioural processes related to vision. Behavioural segmentation of visual attention, for example, can occur during a user's online activity, and the result would be the customisation of specific advertisement banners in relation to colours, shapes, message content, etc. (Hawkins et al., 2009). Other attributes commonly used to form segmentation criteria (age, income, religion, educational level, housing, etc.) may possibly be associated with visual attention behaviour in order to identify its specific patterns.

\subsection{Products}

To be successful, products must meet the needs of the target market better than their competitors (Hawkins et al., 2009). ET can significantly contribute to this goal since it helps us to understand what attracts a customer to that product, the way the customer is related to the product and its packaging, and the positive or negative ways the customer interacts with, consumes, or uses the product.

The opportunities for understanding the brain during the analysis of a design was explored by Stoll, Baecke and Kenning (2008), who analysed the attractiveness of packaging designs using functional magnetic resonance imaging (fMRI) to identify what was happening in the subject's brain. Accordingly, ET has great potential either alone as main search tool or in combination with other equipment that is being used in NM, such as fMRI, PET-SCAN or EEG. ET can help to define the industrial design of products, packaging, and nutrition labels.

Both the product and its packaging influence attention, evaluation, and ultimately, impact whether or notthe consumer decides to purchase the product (Fenko, Schifferstein, \& Hekkert, 2010). Fiszman et al. (2013) reported that although researchers work to innovate when developing new packaging formats, trying to create new multisensory experiences in packaging, many of the new designs are only visually perceptible. Their research was aiming to determine how the packaging elements for a particular brand of jam attracted attention and the immediate message the packaging conveyed. They concluded that certain package elements could be 
used to drive the attention of the consumer. For example, the researchers found that the picture on the packaging label and the bottle shape influenced consumers' willingness to try the product. Their research used ET and a qualitative research method known as word association.

Another study investigated the visual attention behaviour in nutrition information of food labels. With the use of ET, it was possible to identify consumers with two different kinds of characteristics: analytical-rational thinking and intuitive-empirical thinking. Consumers who predominantly used analytical-rational thinking searched for more information and performed a more careful analysis of nutritional information to inform their choices than those consumers who predominantly used intuitive-empirical thinking. These findings have potential implications for the design of communication strategies aimed at changing diet patterns, because it was found that consumers' attention was mainly determined by top-down factors; analytical-rational consumers tend to look for specific information on the labels (Ares et al., 2013).

An additional study investigated how consumers acquire information from food labels through eye tracking. The participants of the study performed two tasks in which they evaluated the perception of how healthy the products appeared to be and their willingness to buy them by observing three unknown labels of three different products (mayonnaise, bread and yogurt). As they assessed the labels, participants' eye movements were recorded by means of ET. The results showed the following: in order to assess their willingness to purchase unknown food labels, consumers turn their attention to selected areas in search of specific information such as brand, ingredients, nutritional information, and the pictures on the labels, regardless of the type of product and label design (Ares, Mawad, Giméneza, \& Maiche, 2013).

ET may also be used in combination with electroencephalogram (EEG) equipment, which identifies brain waves linked to levels of attention and different emotions. During research on the decision processes of consumers, the combined use of these devices attempted to verify the attributes of a sweet that most influenced their decision. The participants read descriptions of the characteristics of three kinds of cookies. An analysis of combined information indicated that the flavours and toppings of cookies were more important factors than their shape in determining the participants' choice to purchase them (Khushaba et al., 2013).

Even using only ET, the data obtained are of great value for the development of products. For example, a study of women selecting ladies' handbags demonstrated the motivation to observe specific parts of the product and identified a clear order of priorities and fixations on different parts of the product. Based on the statistical analysis of fixations, the author came to the following conclusion: the handbag body was the part that first attracted the attention of participants and the handle was the part that received most attention, generating a stronger visual attraction $(\mathrm{Ho}, 2014)$. This line of research provides evidence that eye tracking can be applied to future empirical research into the visual behaviour of consumers.

Research on ET may contribute to the development of new products. From designing the best package in terms of functionality and usability to the development of a new product and the attractiveness of its design, ET has potential uses that are not yet fully exploited by organisations during the development or improvement of their products.

\section{4 Prices}

Understanding the psychology of price is crucial for decision making. The way prices are presented has implications on how people process information in any decision context. A study showed the errors made by consumers when processing prices that end in .99 compared to prices that end in .00 , which suggests that individuals pay less attention to the trailing numbers in a sequence (Bizer \& Schindler, 2005). Moreover, the price displayed to the left or right of an item can influence customers' perceptions of the value of a product (Suri \& Grewal, 2011).

Price promotions are a key marketing tool that retailers use to generate sales and increase their market share (Grewal et al., 2011). Thus, eye-tracking studies can assist in the development of flyers and online or offline sales, helping retailers determine whether to use the selling price, the reference price, a sales slogan, colours, amount in dollars, or amount in percentages.

Consumers tend to process price information in a relative way and not absolute way (Lindsey-Mullikin \& Grewal, 2006). Therefore, they are often more susceptible to $\$ 5$ off a $\$ 10$ item than $\$ 5$ off a $\$ 100$ item. For cheaper items, there is a tendency to value an amount saved in terms of a percentage rather than in terms of currency (Chen, Monroe, \& Lou, 1998). Another study shows that consumers respond to the colour of prices in marketing communications (Grewal et al., 2011). 
There are many possibilities for studies in which ET allows pricing analysis. For example, ET has been used in determining behaviour patterns in reading habits and helped advertisers to format more attractive pricing packages. One research project examined numeric digits and eye movements in order to identify patterns in selective visual attention related to the rounding of prices. The project investigated whether individuals are conscious or not of left-right orientation (front/rear) when reading numeric digits. It was concluded that the use of specific combinations of digits might result in the perception that a price is higher or lower than its actual value (Coulter, 2007).

There are relatively few studies relating price and visual attention. There are still many research opportunities associated with visual attention behaviour, reading behaviour patterns, and other possible ET analyses, including the following: pricing, price changes, price presentation formats (colours, sizes, types of letters, location etc.), use of dollar signs and commas, and other pricing issues.

\subsection{Place and Promotion}

Store marketing is gaining importance for marketing in general, because the competition for consumer attention is increasingly fierce (Shankar, Inman, Mantrala, Kelley, \& Rizley, 2011). Many of the purchasing decisions in supermarkets, for example, are made when consumers are in the store (Point of Purchase Advertising Institute [POPAI], 1997). Consumers only observe and evaluate a fraction of the hundreds of alternatives on supermarket shelves (Inman \& Winer, 1998). The behaviour of consumers at the point of purchase is therefore influenced by visual attention factors: the arrangement of the product on the shelf, colours, and other elements (Wedel \& Pieters, 2008).

Some studies have used ET to investigate the role of various stimuli on the shelves (Chandon, Hutchinson, Bradlow, \& Young, 2009). The ET technology assesses exactly what consumers see and what they miss when they are looking at different categories (Grewal et al., 2011). ET studies may provide insights into which elements are the most important and effective in attracting attention and enhancing sales (Grewal et al., 2011).

Marketing communications that can benefit from new ET studies include advertising, sales force, public relations, packaging, and other signs that the company provides about itself and its products. All stages of communication-strategy development will provide a better understanding of visual behaviour. ET can assist in understanding the best features of messages directed toward certain groups, features such as words, images, symbols as they are used in mass-media advertising (television, radio, interviews, newspapers, and internet), direct mail, and other time-sensitive venues.

For example, one particular study tested the relationship between the colours used on websites and the trust and satisfaction engendered in customers. The study found cultural effects moderating this relationship between colour and customer loyalty. Online satisfaction and trust proved to be strong predictors of online loyalty with respect to colours. Colour choices significantly influenced online trust and satisfaction. Differences were found among subjects that came from several different countries: Japan, Germany and Canada. The study demonstrated that the impact of the variation in colour schemes supports the idea that colour has the potential to influence the perceptions, emotions, reactions and behavioural intentions of users (Cyr, Head, \& Larios, 2010).

In another study, researchers analysed the impact of contrasting colours in the fruit and vegetable market on the attention behaviour of customers. They used ET to determine the perceived quality, visual appeal, and purchase intent of customers. Results were measured using a Likert scale. Six different types of product packaging were photographed with four treatments of different colours: the same original colour of products, variations of complementary packaging colours, complementary-analogous colours and analogous colours. It was concluded that products using packaging with colours that were the same or similar to the fruits and vegetables within the packaging were perceived as higher quality, more visually appealing, and more likely to produce purchase intent than those products with complementary treatments or complementary-analogous treatments (Bix, Seo, \& Sundar, 2013). Therefore, ET helps to increase the perceived value of products through a better understanding of consumer perceptions.

ET was also used to evaluate the effectiveness of marketing emails on people from different demographics, and from various market sectors, in order to identify techniques that could be applied to improve engagement and performance. One study examined 50 emails in eight different categories, including fashion, holidays, daily sales, and Christmas gifts. The researchers discovered the benefits of elaborating on the structure of marketing emails using digital signalling, consumer clicks, key contents, a combination of text and pictures, digital sales techniques, graphic elements, decreased spacing between elements, and the importance of peripheral vision, all of which influence the direction of eye movement (Rowe \& Burridge, 2012). ET can serve as a basis for the 
selection of the best mix of variables, allowing these variables to be optimised to increase the effectiveness of email marketing for different situations and audiences.

Another related study examined the attention of consumers on internet banners to determine the effectiveness of these banners. The results suggest that animation in banners does not necessarily increase the user's attention but even if the user does not consciously notice a banner, his attitude toward the brand is influenced (Lee \& Ahn, 2012). An additional study examined the effect of stimuli on consumers' attention to print ads. The results showed that the focus of the reader's visual attention can be efficiently directed by using certain techniques (Hutton \& Nolte, 2011).

Considering its potential, there are a relatively small number of studies of ET but ET is already attracting the attention of marketers in areas not previously considered. It is possible to perform observational studies in situations without any interference from researchers. This occurs with portable or stationary ET equipment in public places with high foot traffic, like a sidewalk near a storefront window. This format of visual attention identification will revolutionise the way that companies will address store layout, show windows, or the arrangement of products on a shelf.

\subsection{Social Marketing}

Social marketing is an area that employs marketing techniques aimed at achieving socially desirable outcomes (Donovan, 2011). Social marketing aims to encourage a variety of positive behaviours, such as mass media advertisements that warn the general public of the dangers of drug use, or the consequences of driving under the influence of alcohol (Grier \& Bryant, 2005). ET studies may contribute to the improvement of these ads by analysing their messages and the behaviour of their target audience. For example, efforts to understand the difference between the visual attention of smokers and that of non-smokers would be a great candidate for ET (Baschnagel, 2013).

In this line of research, one study investigated the visual attention of adolescents (aged 14-19) on the health warnings displayed on cigarette packages. Some of the adolescents had never smoked, some were experimenters, some were weekly smokers and others smoked daily. It was concluded that adolescents who never smoked paid attention to health warnings in different types of packaging, a behaviour that may be related to their decision not to smoke. The behaviour of smokers was quite different (Maynard, Munafò, \& Leonards, 2013). A better understanding of the visual attention of smokers and non-smokers can aid in the effectiveness of specific campaigns for these groups of adolescents.

Another social problem being studied is the irresponsible consumption of alcoholic beverages. A study conducted using adolescents investigated whether they pay attention to messages about responsibility and moderation that appear in magazine advertisements for alcoholic beverages. The study evaluated the association between attention and the subjects' ability to accurately recall the content of these messages. In general, the messages were the rarely viewed. Beverage bottles, product logos, and graphics were the elements most often seen in the ads. One of the conclusions of the study was that messages about responsibility and moderation failed to capture the attention of adolescents who participated in the study and that further typo graphical modification would be needed to make the messages more effective (Thomsen \& Fulton, 2007).

Clearly, ET can be used in Social Marketing, potentially increasing the effectiveness of social communication in different media and encouraging a deeper understanding of positive or negative attitudes toward social issues.

\section{Final Remarks}

This paper has shown the potential of Eye Tracking for neuromarketing research and for the development of marketing in general. The use of Eye Tracking and Neuromarketing in marketing analysis is becoming increasingly popular and shows great potential for aiding market research, innovation, product development, advertising, sales, customer service, loyalty programs, and various other marketing topics.

Eye-tracking in market research can provide insights into participants' habits even when these participants are not aware that they are being observed. This information is mainly related to what should attract visual attention or visual behaviour in different situations. Other qualitative techniques can also be used in combination with eyetracking to provide more information about the cognitive and affective responses of consumers.

This study demonstrates that there is a wide range of possibilities for the use of eyetracking in neuromarketing and visual neuroscience. Further visual attention studies related to brand equity, segmentation, new product development, pricing decisions, place and promotion, and social marketing should be carried out to highlight this potential. Other studies and lines of research that were not listed may also be conducted. Since Neuromarketing and Eye Tracking are becoming increasingly popular in academia and the business world, clearly there are other 
research possibilities yet to be identified. In conclusion, it can be inferred that, with all this potential, we can expect the increasingly frequent use of this equipment and this line of research, which will soon become a part of mainstream marketing.

\section{References}

Ares, G., Giménez, A., Bruzzone, F., Vidal, L., Antúnez, L., \& Maiche, A. (2013). Consumer visual processing of food labels: Results from an eye-tracking study. Journal of Sensory Studies, 28, 138-153. http://dx.doi.org/10.1111/joss.12031

Ares, G., Mawad, F., Giméneza, A., \& Maiche, A. (2013). Influence of rational and intuitive thinking styles on food choice: Preliminary evidence from an eye-tracking study with yogurt labels. Food Quality and Preference, 31, 28-37. http://dx.doi.org/10.1016/j.foodqual.2013.07.005

Baschnagel, J. S. (2013). Using mobile eye-tracking to assess attention to smoking cues in a naturalized environment. Addictive Behaviors, 38, 2837-2840. http://dx.doi.org/10.1016/j.addbeh.2013.08.005

Behe, B. K., Zhao, J., Sage, L., Huddleston, P. T., \& Minahan, S. (2013). Display signs and involvement: The visual path to purchase intention. International Review of Retail, Distribution and Consumer Research, 23, 511-522. http://dx.doi.org/10.1080/09593969.2013.832695

Bercea, M. D. (2013). Quantitative versus qualitative in neuromarketing research (Munich Personal RePEc Archive, Paper No. 44134, pp. 1-12). Retrieved from http://mpra.ub.uni-muenchen.de/44134/1/MPRA_paper_44134.pdf

Bix, L., Seo, W., \& Sundar, R. P. (2013). The effect of colour contrast on consumers' attentive behaviours and perception of fresh produce. Packaging Technology and Science, 26, 96-104. http://dx.doi.org/10.1002/pts.1972

Bizer, G. Y., \& Schindler, R. M. (2005). Direct evidence of ending-digit drop-off in price information processing. Psychology \& Marketing, 22, 771-802. http://dx.doi.org/10.1002/mar.20084

Brasel, S. A., \& Gips, J. (2008). Breaking through fast-forwarding: Brand information and visual attention. Journal of Marketing, 72(6), 31-48.

Butler, M. J. (2008). Neuromarketing and the perception of knowledge. Journal of Consumer Behaviour, 7 , 415-419. http://dx.doi.org/10.1002/cb.260

Calvert, G. A., \& Brammer, M. J. (2012). Predicting consumer behavior: Using novel mind-reading approaches. IEEE Pulse, 3(3), 38-41.

Chae, S. W., \& Lee, K. C. (2013). Exploring the effect of the human brand on consumers' decision quality in online shopping: An eye-tracking approach. Online Information Review, 37, 83-100.

Chandon, P., Hutchinson, J. W., Bradlow, E. T., \& Young, S. H. (2009). Does in-store marketing work? Effects of the number and position of shelf facings on brand attention and evaluation at the point of purchase. Journal of Marketing, 76(6), 1-17. http://dx.doi.org/10.1509/jmkg.73.6.1

Chen, S. F., Monroe, K. B., \& Lou, Y. C. (1998). The effects of framing price promotion messages on consumers' perceptions and purchase intentions. Journal of Retailing, 74, 353-372. http://dx.doi.org/10.1016/S0022-4359(99)80100-6

Coulter, K. S. (2007). The effects of digit-direction on eye movement bias and price rouding behavior. Journal of Product and Brand Management, 16, 501-508.

Cyr, D., Head, M., \& Larios, H. (2010). Colour appeal in website design within and across cultures: A multi-method evaluation. International Journal of Human-Computer Studies, 68, 1-21. http://dx.doi.org/10.1016/j.ijhcs.2009.08.005

Donovan, R. (2011). Social marketing's mythunderstandings. Journal of Social Marketing, 1, 8-16.

Duchowski, A. T. (2003). Eye tracking methodology: Theory and pratice. New York, NY: Springer.

Fenko, A., Schifferstein, H. N. J., \& Hekkert, P. (2010). Shifts in sensory dominance between various stages of user-product interactions. Applied Ergonomics, 41, 34-40. http://dx.doi.org/10.1016/j.apergo.2009.03.007

Fiszman, B. P., Velasco, C., Salgado-Montejo, A., \& Spence, C. (2013). Using combined eye tracking and word association in order to assess novel packaging solutions: A case study involving jam jars. Food Quality and Preference, 28, 328-338. http://dx.doi.org/10.1016/j.foodqual.2012.10.006 
Fugate, D. L. (2008). Marketing services more effectively with neuromarketing research: A look into the future. Journal of Services Marketing, 22, 170-173. http://dx.doi.org/10.1108/08876040810862903

Glimcher, P. W., Camerer, C. F., Fehr, E., \& Poldrack, R. A. (2009). Introduction:A brief history of neuroeconomics. In P. W. Glimcher, C. F. Camerer, E. Fehr, \& R. A. Poldrack (Eds.), Neuroeconomics: Decision making the brain (pp. 1-12). San Diego, CA: Academic Press.

Grewal, D., Ailawadi, K. L., Gauri, D., Hall, K., Kopalle, P., \& Robertson, J. R. (2011). Innovations in retail $\begin{array}{llll}\text { pricing and promotions. Journal of Retailing, } & \text { 87(Suppl. 1), S43-S52. }\end{array}$ http://dx.doi.org/10.1016/j.jretai.2011.04.008

Grier, S., \& Bryant, C. A. (2005). Social marketing in public health. Annual Reviews of Public Health, 26, 319-339. http://dx.doi.org/10.1146/annurev.publhealth.26.021304.144610

Hawkins, D. I., Mothersbaugh, D. L., \& Best, R. J. (2009). Consumer behavior: Building marketing strategy. NewYork, NY: McGraw-Hill.

Hill, D. (2011). Emotionomics: Leveraging emotions for business success (2nd ed.). London, United Kingdom: Kogan Page.

Ho, H. F. (2014). The effects of controlling visual attention to handbags for women in online shops: Evidence from eye movements. Computers in Human Behavior, 30, 146-152. http://dx.doi.org/10.1016/j.chb.2013.08.006

Hoffman, J., \& Subramaniam, B. (1995). The role of visual attention in saccadic eye movements. Perception \& Psychophysics, 57, 787-795.

Hubert, M., \& Kenning, P. (2008). A current overview of consumer neuroscience. Journal of Consumer Behaviour, 7, 272-292. http://dx.doi.org/10.1002/cb.251

Hurley, R. A., Ouzts, A., Fischer, J., \& Gomes, T. (2013). Effects of private and public label packaging on consumer purchase patterns. Packaging Technology and Science, 26, 399-412. http://dx.doi.org/10.1002/pts.2012

Hutton, S. B., \& Nolte, S. (2011). The effect of gaze cues on attention to print advertisements. Applied Cognitive Psychology, 25, 887-892. http://dx.doi.org/10.1002/acp.1763

Inman, J. J., \& Winer, R. S. (1998). Where the rubber meets the road: A model of in-store consumer decision-making. Journal of Consumer Research, 25, 290-301.

Javor, A., Koller, M., \& Lee, N. (2013). Neuromarketing and consumer behavior: Contributions to neurology. BMC Neurology, 13, 13. http://dx.doi.org/10.1186/1471-2377-13-13

Khushaba, R. N., Wise, C., Kodagoda, S., Louviere, J., Kahn, B. E., \& Townsend, C. (2013). Consumer neuroscience: Assessing the brain response to marketing stimuli using electroencephalogram (EEG) and eye tracking. Expert Systems with Applications, 40, 3803-3812. http://dx.doi.org/10.1016/j.eswa.2012.12.095

Kotler, P., \& Keller, K. L. (2009). Marketing management (13th ed.). Upper Saddle River, NJ: Pearson Prentice Hall.

Lee, J., \& Ahn, J. H. (2012). Attention to banner ads and their effectiveness: An eye-tracking approach. International Journal of Electronic Commerce, 17(1), 119-137.

Lindsey-Mullikin, J., \& Grewal, D. (2006). Imperfect information: The persistence of price dispersion on the web. Journal of the Academy of Marketing Science, 34, 236-243. http://dx.doi.org/10.1177/0092070305283366

Martinez, P. (2011). The consumer mind: Brand perception and the implication for marketers. London, United Kingdom: Kogan Page.

Maynard, O. M., Munafò, M. R., \& Leonards, U. (2013). Visual attention to health warnings on plain tobacco packaging in adolescent smokers and non-smokers. Addiction, 108, 413-419.

Morin, C. (2011). Neuromarketing: The new science of consumer behavior. Society, 48, 131-135. http://dx.doi.org/10.1007/s12115-010-9408-1

Nielsen, J., \& Pernice, K. (2009). Eyetracking web usability. In Berkeley. CA: New Riders.

Orquín, J. L., \& Loose, S. M. (2013). Attention and choice: A review on eye movements in decision making. Acta Psychologica, 144, 190-206. http://dx.doi.org/10.1016/j.actpsy.2013.06.003 
Page, G. (2012). Scientific realism: What 'neuromarketing' can and can't tell us about consumers. International Journal of Market Research, 54, 287-290.

Pieters, R., \& Wedel, M. (2004). Attention capture and transfer in advertising. Brand, pictorial, and text-size effects. Journal of Marketing, 68(2), 36-50. http://dx.doi.org/10.1509/jmkg.68.2.36.27794

Point of Purchase Advertising Institute. (1997). Consumer buying habits study. Washington, DC: POPAI.

Reimann, M., Schilke, O., Neuhaus, C., Weber, B., \& Zaichkowsky, J. (2011). Functional magnetic resonance imaging in consumer research: A review and application. Psychology \& Marketing, 28, 608-637. http://dx.doi.org/10.1108/13522750710740817

Rowe, A., \& Burridge, L. (2012). Ten inbox secrets: What eye tracking reveals about designing better emails. Journal of Direct, Data and Digital Marketing Practice, 14, 46-65. http://dx.doi.org/10.1057/dddmp.2012.23

Russo, J. E. (1978). Eye fixations can save the world: A critical evaluation and a comparison between eye fixations and other information processing methodologies. Advances in Consumer Research, 5, 561-570.

Shankar, V., Inman, J. J., Mantrala, M., Kelley, E., \& Rizley, R. (2011). Innovations in shopper marketing: Current insights and future research issues. Jornal of Retailing, 87(Suppl. 1), S29-S42. http://dx.doi.org/10.1016/j.jretai.2011.04.007

Solnais, C., Andreu-Perez, J., Sánchez-Fernández, J., \& Andréu-Abela, J. (2013). The contribution of neuroscience to consumer research: A conceptual framework and empirical review. Journal of Economic Psychology, 36, 68-81. http://dx.doi.org/10.1016/j.joep.2013.02.011

Stoll, M., Baecke, S., \& Kenning, P. (2008). What they see is what they get? An fMRI-study on neural correlates of attractive packaging. Journal of Consumer Behaviour, 7, 342-359. http://dx.doi.org/10.1002/cb.256

Suri, R. D., \& Grewal, D. (2011). When left is right and right maybe wrong (Working Paper). Babson Park, MA: Babson College.

Teixeira, T., Wedel, M., \& Pieters, R. (2012). Emotion-induced engagement in Internet video advertisements. Journal of Marketing Research, 49, 144-159. http://dx.doi.org/10.1509/jmr.10.0207

Thomsen, S. R. P. D., \& Fulton, K. B. A. (2007). Adolescents' attention to responsibility messages in magazine alcohol advertisements: An eye-tracking approach. Journal of Adolescent Health, 41, 27-34. http://dx.doi.org/10.1016/j.jadohealth.2007.02.014

Tobii Technology. (2013). Retrieved from http://www.tobii.com/en/eye-tracking-research/global/

Van Praet, D. (2012). Unconscious branding: How neuroscience can empower (and inspire) marketing. New York, NY: Palgrave Macmillan.

Vashishta, D. S., \& Balaji, B. (2012). Social cognitive neuroscience, marketing persuasion and customer

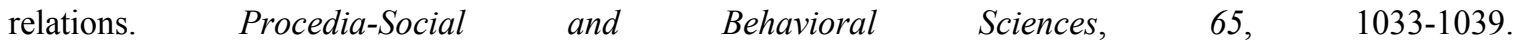
http://dx.doi.org/10.1016/j.sbspro.2012.11.238

Velásquez, J. D. (2013). Combining eye-tracking technologies with web usage mining for identifying Website Keyobjects. Engineering Applications of Artificial Intelligence, 26, 1469-1478. http://dx.doi.org/10.1016/j.engappai.2013.01.003

Venkatraman, V., Clithero, J. A., Fitzsimons, G. J., \& Huettel, S. A.(2012). New scanner data for brand marketers: How neuroscience can help better. Journal of Consumer Psychology, 22, 143-153. http://dx.doi.org/10.1016/j.jcps.2011.11.008

Wedel, M., \& Pieters, R. (2008). Visual marketing: From attention to action. New York, NY: Taylor \& Francis.

Zhao, Q., \& Koch, C. (2013). Learning saliency-based visual attention: A review. Signal Processing, 93, 1401-1407. http://dx.doi.org/10.1016/j.sigpro.2012.06.014

Zurawicki, L. (2010). Neuromarketing: Exploring the brain of the consumer. Boston, MA: Springer.

\section{Copyrights}

Copyright for this article is retained by the author(s), with first publication rights granted to the journal.

This is an open-access article distributed under the terms and conditions of the Creative Commons Attribution license (http://creativecommons.org/licenses/by/3.0/). 